\title{
Risk of perioperative death and sudden cardiac arrest: A study of 113456 cases from the National Registry of Invasive Cardiology Procedures (ORPKI) for estimation of the perioperative prognosis
}

\author{
Janusz Sielski, Karol Kaziród-Wolski, Zbigniew Siudak \\ Collegium Medicum, Jan Kochanowski University, Kielce, Poland
}

\author{
Correspondence to: \\ Karol Kaziród-Wolski, MD, PhD, \\ Collegium Medicum, \\ Jan Kochanowski University, \\ IX Wieków Kielc 19A, \\ 25-516 Kielce, Poland, \\ phone: +48 413496911 , \\ e-mail:karol.kazirod-wolski@ \\ ujk.edu.pl \\ Copyright by the Author(s), 2021 \\ Kardiol Pol. 2021; \\ 79 (12): 1328-1334; \\ DOI: 10.33963/KP.a2021.0133 \\ Received: \\ May 3, 2021 \\ Revision accepted: \\ October 11, 2021 \\ Published online: \\ October 12, 2021
}

\section{A B S TRACT}

Background: Despite optimizing treatment of ST-segment elevation myocardial infarction (STEMI), a number of patients die during the invasive procedure or experience sudden cardiac arrest (SCA) that complicates further hospitalization.

Aims: This study aimed to identify the most important risk factors leading to SCA and death in the cath lab among STEMI patients.

Methods: We used data from the National Registry of Invasive Cardiology Procedures (ORPKI) collected between 2014 and 2019. The study population consisted of 113465 patients. Descriptive statistics, univariate and multiple logistic regression analysis of factors affecting perioperative mortality (PM) and SCA in the cath lab were performed.

Results: Death and SCA occurred in 1549 (1.4\%) and 945 (0.8\%) patients, respectively. Diabetes (odds ratio $[\mathrm{OR}], 1.76 ; P<0.0001)$, previous brain stroke $(\mathrm{OR}, 2.26 ; P<0.0001)$, prior myocardial infarction $(\mathrm{OR}, 1.81 ; P<0.0001)$, psoriasis $(\mathrm{OR}, 1.79 ; P=0.04)$, and chronic renal failure $(\mathrm{OR}, 2.79 ; P<0.0001)$ were the strongest predictors of $P M$. The occurrence of SCA was dependent mainly on diabetes $(\mathrm{OR}, 1.37 ; P=0.0001)$, previous brain stroke $(\mathrm{OR}, 2.23 ; P<0.0001)$, prior myocardial infarction (OR, $1.73 ; P<0.0001)$, psoriasis $(\mathrm{OR}, 2.03 ; P=0.04)$, and chronic renal failure $(\mathrm{OR}, 2.79 ; P<0.0001)$. Of the pre-hospital factors, the Killip-Kimball class showed the strongest relationship with the two endpoints (OR 3.53; $P<0.0001$ and OR 2.65; $P<0.0001$, respectively).

Conclusions: Diabetes, previous brain stroke, myocardial infarction, psoriasis, chronic renal failure, and the Killip-Kimball class were the strongest predictors of PM and SCA in the cath lab among STEMI patients.

Key words: periprocedural mortality, risk factors, STEMI

Kardiol Pol 2021; 79, 12: 1328-1334

\section{INTRODUCTION}

Out-of-hospital cardiac arrest (OHCA) remains a major clinical challenge. According to various studies, survival after an OHCA ranges from 5.7 to $8.3 \%$ [1, 2]. OHCA is an acute event that can potentially affect any hospitalized patient. For clinical care, research, and practice guideline development, in-hospital cardiac arrest is most commonly defined as the loss of circulation prompting resuscita- tion with chest compression, defibrillation, or both [3]. In-hospital cardiac arrest occurs in over 290000 adults each year in the United States. The mean age of these patients is 66 years, $58 \%$ are men $[4,5]$. The causes of the arrest are most commonly cardiac (50\%-60\%), whereas respiratory insufficiency accounts for $15 \%-40 \%$ of cases. The basic elements of treatment during in-hospital cardiac arrest include external cardiac massage, ventilation, 
WHAT'S NEW?

A large number of studies have identified numerous predictors of short-term mortality in patients with ST-segment elevation myocardial infarction (STEMI). The present investigation, relying on a large and reliable national database, describes the most significant factors affecting periprocedural mortality and sudden cardiac arrest in STEMI patients and compares two statistical models (based on comorbidities, as well as pre-hospital and pharmacological factors). A better understanding of these factors facilitates the preparation of the team for optimal patient care.

early defibrillation, and correction of hypokalemia and hypoxia [6].

Perioperative cardiac arrest is a separate entity with its own incidence, diagnosis, and treatment. The incidence of OHCA associated with ST-segment elevation myocardial infarction (STEMI) oscillates between 8 and 10\% [7, 8]. In recent years, outcomes in such patients have generally improved. However, patients after an OHCA and with cardiac arrest in the catheterization laboratory (cath lab) are at high risk of mortality despite treatment with emergent coronary revascularization and other aggressive options $[9,10]$.

Sweden has the most complete STEMI registry in Europe. According to the 2015 report the incidence rate for STEMI was 58 cases/100 000 per year [11]. Other European countries report the incidence rate of around 43-144 cases/100 000 per year [12].

Cardiac arrest in the cath lab among STEMI patients has not been studied extensively in Poland so far. The purpose of the present study is to describe patients experiencing cardiac arrest in the cath lab based on the data from the National Registry of Invasive Cardiology Procedures (ORPKI).

\section{METHODS}

This study aims to identify risk factors that can lead to cardiac arrest and death in the cath lab among patients with STEMI in the era of the increased availability of cardiac catheterization facilities in Poland and reduced perioperative mortality (PM) rates.

Data in the ORPKI have been collected since 2004. The electronic ORPKI was launched on January 1, 2014. The database was created by the Association of Cardiovascular Interventions of the Polish Cardiac Society. At the moment, the registry is coordinated by the Jagiellonian University Medical College in Krakow, which collects data from 161 catheterization labs in Poland. For the analysis, data from 2014 to 2019 were extracted from the database. The study population consisted of patients admitted to the hospital in compliance with the guidelines of the Polish Cardiac Society and selected for invasive treatment of acute coronary syndromes with persistent ST-segment elevation. After the exclusion of cases with missing data, the study group consisted of 113465 participants. Patients who died or experienced cardiac arrest in the cath lab were identified among participants. We conducted a pooled analysis of comorbidities in patients with STEMI, predisposing factors, and the medications used to treat STEMI. Initial aspirin doses were skipped in patients already undergoing chronic acetylsalicylic acid (ASA) therapy.

Chronic renal failure was defined in compliance with the recommendations as the presence of an eGFR (estimated glomerular filtration rate) of less than $60 \mathrm{ml} / \mathrm{min} / 1.73 \mathrm{~m}^{2}$. The ORPKI registry accumulated information on cardiac arrest and sudden cardiac death, but not on their mechanism (ventricular tachycardia/ventricular fibrillation [VT/VF], asystole, and pulseless electrical activity). Cardiac arrest occurred either prior to hospitalization (out-of-hospital cardiac arrest) thus qualifying the patient for invasive therapy or during hospitalization in the cath lab. Univariate and multiple logistic regression analysis of clinical, pre-hospital, and pharmacological factors affecting perioperative mortality and cardiac arrest in the cath lab was also performed. The study was carried out in accordance with the ethical standards of the 1964 Declaration of Helsinki. All conscious patients had been informed about the invasive procedure and gave their consent before treatment. If a patient was unconscious, the decision was made by two specialists in compliance with the current recommendations in emergencies to prevent death. The study was exempt from the bioethics committee approval as it used anonymous data from the ORPKI Registry.

\section{Statistical analysis}

Quantitative variables were expressed as median (interquartile range $[\mathrm{QQR}])$. Categorical variables were presented as numbers and percentages. The normality of data distribution was tested with the Kolmogorov-Smirnov test. The $\mathrm{x} 2$ test was used to test the interdependence between pairs of variables for double classifications. The Mann-Whitney test for non-normally distributed variables was used to assess within-group differences. The univariate and multiple logistic regression models were used to estimate odds ratios with $95 \%$ confidence intervals and $P$-values. The FORWARD (enter significant variables sequentially) option was used to select variables for the model. The receiver operating characteristic analysis was used to estimate the fit of multivariable logistic regression models based on predicted probabilities of logistic models. The comparisons of areas under curves (AUC) are presented in a graphical form. A Z statistic was used for comparing AUCs. A P-value less than 0.05 was considered significant. Statistical analysis was performed using the Med-Calc Statistical Software 20, version 19.7 (MedCalc Software, Ostend, Belgium) [13]. 
Table 1. Clinical factors affecting the occurrence of periprocedural death

\begin{tabular}{|c|c|c|c|c|}
\hline \multirow[t]{2}{*}{ Variable } & \multicolumn{2}{|c|}{ Univariate (unadjusted) } & \multicolumn{2}{|c|}{ Multivariable (adjusted)a } \\
\hline & OR $(95 \% \mathrm{CI})$ & $P$-value & OR $(95 \% \mathrm{Cl})$ & $P$-value \\
\hline Age, years & $1.05(1.04-1.05)$ & $<0.001$ & $1.04(1.03-1.04)$ & $<0.001$ \\
\hline Male gender & $0.61(0.55-0.68)$ & $<0.001$ & $0.83(0.75-0.93)$ & 0.01 \\
\hline Diabetes & $1.76(1.57-1.97)$ & $<0.001$ & $1.55(1.37-1.75)$ & $<0.001$ \\
\hline Previous stroke & $2.26(1.86-2.76)$ & $<0.001$ & $1.58(1.29-1.94)$ & $<0.001$ \\
\hline Previous MI & $1.81(1.60-2.05)$ & $<0.001$ & $1.88(1.59-2.23)$ & $<0.001$ \\
\hline Previous PCl & $1.30(1.13-1.50)$ & $<0.001$ & $0.81(0.67-0.97)$ & 0.03 \\
\hline Previous CABG & $1.54(1.13-2.09)$ & 0.01 & \multicolumn{2}{|c|}{$\mathrm{NI}$} \\
\hline Active smoking status & $0.45(0.39-0.51)$ & $<0.001$ & $0.68(0.59-0.78)$ & $<0.001$ \\
\hline Psoriasis & $1.79(1.03-3.11)$ & 0.04 & $2.07(1.19-3.63)$ & 0.01 \\
\hline Hypertension & $0.71(0.65-0.79)$ & $<0.001$ & $0.52(0.47-0.58)$ & $<0.001$ \\
\hline Chronic renal failure & $2.79(2.34-3.33)$ & $<0.001$ & $1.67(1.39-2.01)$ & $<0.001$ \\
\hline COPD & $1.33(0.95-1.86)$ & 0.09 & \multicolumn{2}{|c|}{$\mathrm{NI}$} \\
\hline
\end{tabular}

aMultivariable logistic regression, adjusting for other factors shown in the table; Significant variables entered sequentially (Forward option)

Abbreviations: $\mathrm{CABG}$, coronary artery bypass grafting; $\mathrm{Cl}$, confidence interval; $\mathrm{COPD}$, chronic obstructive pulmonary disease; $\mathrm{Ml}$, myocardial infarction; $\mathrm{NI}$, not included; $\mathrm{OR}$, odds ratio; $\mathrm{PCl}$, percutaneous coronary intervention

Table 2. Clinical factors affecting the occurrence of cardiac arrest

\begin{tabular}{|c|c|c|c|c|}
\hline \multirow[t]{2}{*}{ Variable } & \multicolumn{2}{|c|}{ Univariate (unadjusted) } & \multicolumn{2}{|c|}{ Multivariable (adjusted) ${ }^{a}$} \\
\hline & OR $(95 \% \mathrm{CI})$ & $P$-value & OR $(95 \% \mathrm{CI})$ & $P$-value \\
\hline Age, year & $1.02(1.02-1.03)$ & $<0.001$ & $1.02(1.01-1.02)$ & $<0.001$ \\
\hline Male gender & $0.74(0.65-0.85)$ & $<0.001$ & $0.83(0.73-0.96)$ & 0.01 \\
\hline Diabetes & $1.37(1.17-1.60)$ & $<0.001$ & $1.26(1.07-1.48)$ & 0.01 \\
\hline Previous stroke & $2.23(1.73-2.87)$ & $<0.001$ & $1.85(1.44-2.40)$ & $<0.001$ \\
\hline Previous MI & $1.73(1.48-2.04)$ & $<0.001$ & $2.04(1.64-2.54)$ & $<0.001$ \\
\hline Previous $\mathrm{PCl}$ & $1.24(1.03-1.49)$ & 0.03 & $0.73(0.57-0.94)$ & 0.02 \\
\hline Previous CABG & $1.34(0.88-2.03)$ & 0.17 & \multicolumn{2}{|c|}{$\mathrm{NI}$} \\
\hline Active smoking status & $0.76(0.65-0.88)$ & $<0.001$ & \multicolumn{2}{|c|}{$\mathrm{NI}$} \\
\hline Psoriasis & $2.03(1.05-3.93)$ & 0.04 & $2.13(1.10-4.14)$ & 0.03 \\
\hline Hypertension & $0.85(0.75-0.97)$ & 0.01 & $0.71(0.62-0.81)$ & $<0.001$ \\
\hline Chronic renal failure & $1.80(1.38-2.36)$ & $<0.001$ & \multicolumn{2}{|c|}{$\mathrm{NI}$} \\
\hline COPD & $1.33(0.87-2.04)$ & 0.19 & \multicolumn{2}{|c|}{$\mathrm{NI}$} \\
\hline
\end{tabular}

aMultivariable logistic regression, adjusting for other factors shown in the table; Significant variables entered sequentially (Forward option)

Abbreviations: see Table 1

\section{RESULTS}

We analyzed the ORPKI data from 2014 to 2019 , and a total of 113456 patients with STEMI were selected for invasive treatment. In this group, periprocedural death occurred in 1549 (1.4\%) patients. Cardiac arrest during the procedure occurred in $0.8 \%$ of patients. The remaining $0.6 \%$ of deaths occurred in patients which were in agonal state when all treatment options were exhausted. Table S1 (Supplementary material) summarizes the prevalence of comorbidities in STEMI patients who died in the cath lab and experienced periprocedural cardiac arrest. Table S2 (Supplementary material) shows the use of antiplatelet agents and the distribution of selected pre-hospital and pharmacological factors. PM/sudden cardiac arrest was most strongly related to a history of diabetes, prior myocardial infarction and stroke, psoriasis, and a history of renal failure (Table 1). Among the pre-hospital and pharmacological factors, the most significant relationship was seen when comparing perioperative mortality between patients with higher
Killip-Kimball classes in whom time from the onset of pain to the first medical contact, time from the onset of pain to an angiogram, and time from the first medical contact to an angiogram was prolonged (Table 2). Of the pre-hospital and pharmacological factors, patients with heart failure in the higher Killip-Kimball class were at increased risk of $\mathrm{PM}$ /cardiac arrest in the cath lab (Table 3). Analysis of the two groups of factors i.e., clinical/pharmacological and procedural factors, revealed higher sensitivity and specificity of the model based on the clinical factors for prediction of both perioperative mortality and cardiac arrest. Results are shown in Figure 1 and Figure 2.

\section{DISCUSSION}

Before the COVID-19 pandemic, several national registries were available to explore the effect of various factors on the management of STEMI. One such example is ORPKI.

Previous research, similar to ours, usually estimated medium- and long-term risk [14, 15]. However, it is equally 
Table 3. Pre-hospital and pharmacological risk factors affecting the occurrence of cardiac arrest and perioperative death

\begin{tabular}{|c|c|c|c|c|c|c|c|c|}
\hline \multirow[t]{3}{*}{ Variable } & \multicolumn{4}{|c|}{ Death during procedure } & \multicolumn{4}{|c|}{ Cardiac arrest during procedure } \\
\hline & \multicolumn{2}{|c|}{ Univariate (unadjusted) } & \multicolumn{2}{|c|}{ Multivariable (adjusted) ${ }^{a}$} & \multicolumn{2}{|c|}{ Univariate (unadjusted) } & \multicolumn{2}{|c|}{ Multivariable (adjusted) ${ }^{a}$} \\
\hline & OR $(95 \% \mathrm{CI})$ & $P$-value & OR (95\% CI) & $P$-value & OR $(95 \% \mathrm{Cl})$ & $P$-value & OR $(95 \% \mathrm{Cl})$ & $P$-value \\
\hline ASA & $0.57(0.51-0.64)$ & $<0.001$ & $1.19(1.03-1.38)$ & 0.02 & $0.71(0.61-0.82)$ & $<0.001$ & $\mathrm{NI}$ & \\
\hline Heparin & $0.80(0.70-0.91)$ & $<0.001$ & $\mathrm{NI}$ & & $1.06(0.88-1.27)$ & 0.56 & $1.29(1.07-1.57)$ & $<0.001$ \\
\hline P2Y12 inhibitor & $0.37(0.34-0.41)$ & $<0.001$ & $0.40(0.35-0.46)$ & $<0.001$ & $0.57(0.49-0.65)$ & $<0.001$ & $0.62(0.53-0.72)$ & $<0.001$ \\
\hline GP IIb/IIla inhibitor & $1.06(0.95-1.18)$ & 0.28 & $0.83(0.74-0.93)$ & 0.01 & $1.23(1.08-1.41)$ & 0.01 & $\mathrm{NI}$ & \\
\hline $\begin{array}{l}\text { Time from pain to first contact, hours } \\
(\leq 12 ; 12-48 ;>48)\end{array}$ & $1.33(1.23-1.45)$ & $<0.001$ & $1.37(1.25-1.50)$ & $<0.001$ & $0.83(0.72-0.96)$ & 0.01 & $0.85(0.74-0.98)$ & 0.03 \\
\hline $\begin{array}{l}\text { Time from pain to inflation or angio- } \\
\text { gram, hours }(\leq 12 ; 12-48 ;>48)\end{array}$ & $1.32(1.13-1.54)$ & $<0.001$ & $\mathrm{NI}$ & & $0.95(0.74-1.23)$ & 0.70 & $\mathrm{NI}$ & \\
\hline $\begin{array}{l}\text { Time from first contact to inflation or } \\
\text { angiogram, hours }(\leq 12 ; 12-48 ;>48)\end{array}$ & $1.31(1.19-1.44)$ & $<0.001$ & $\mathrm{NI}$ & & $0.83(0.70-0.98)$ & 0.03 & $\mathrm{NI}$ & \\
\hline Direct transport to cath lab & $1.32(1.18-1.47)$ & $<0.001$ & $1.22(1.09-137)$ & 0.01 & $1.83(1.60-2.08)$ & $<0.001$ & $1.65(1.45-1.89)$ & $<0.001$ \\
\hline Killip-Kimball Class (I-IV) & $3.53(3.39-3.68)$ & $<0.001$ & $3.47(3.33-3.61)$ & $<0.001$ & $2.65(2.52-2.78)$ & $<0.001$ & $2.57(2.44-2.70)$ & $<0.001$ \\
\hline
\end{tabular}

aMultivariable logistic regression, adjusting for other factors shown in the table; Significant variables entered sequentially (Forward option) Abbreviations: ASA, acetylosalicylic acid; GPI glycoprotein inhibitor; other — see Table 1

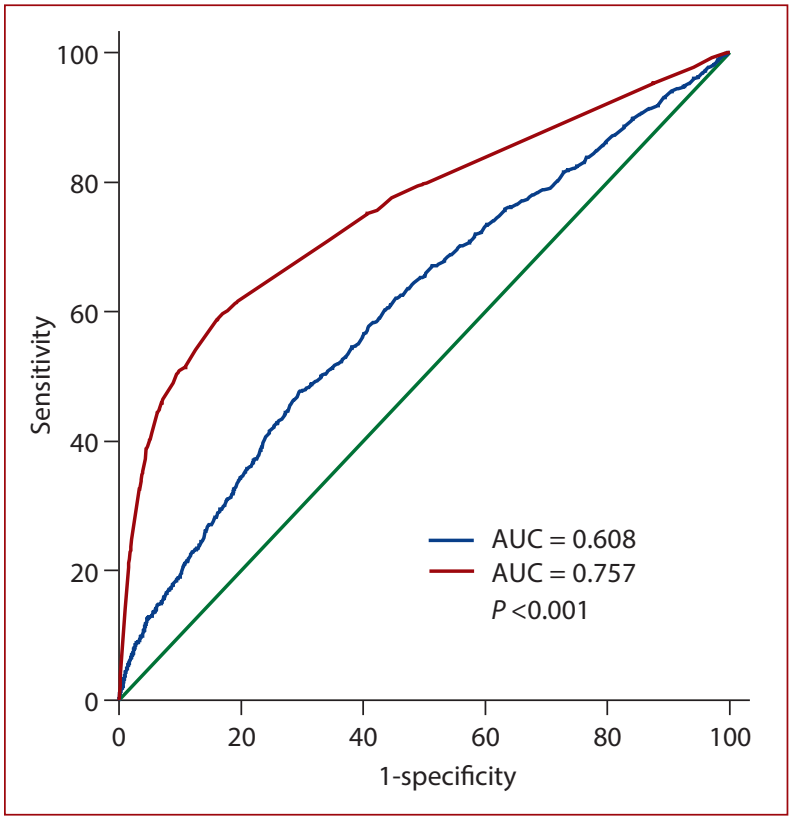

Figure 1. Pairwise comparison of ROC curves for the multivariable logistic regression model for cardiac arrest during the procedure based on (1) clinical factors and (2) pre-hospital and pharmacological factors

Abbreviations: AUC, area under the curve; ROC, receiver operating characteristic

important to determine perioperative risk, especially in studies involving larger groups of patients and lasting for many years. For instance, Siudak et al. [16] and Tokarek et al. [17] evaluated a number of factors that could affect the management of acute coronary syndromes within the context of the perioperative environment. Diabetes, chronic renal failure, prior myocardial infarction, and psoriasis were the factors that were found to influence perioperative outcomes significantly.

The effect of diabetes on prognosis in STEMI patients has been very well documented in the Thrombus Aspiration in ST-Elevations myocardial infarction in the Scandinavia

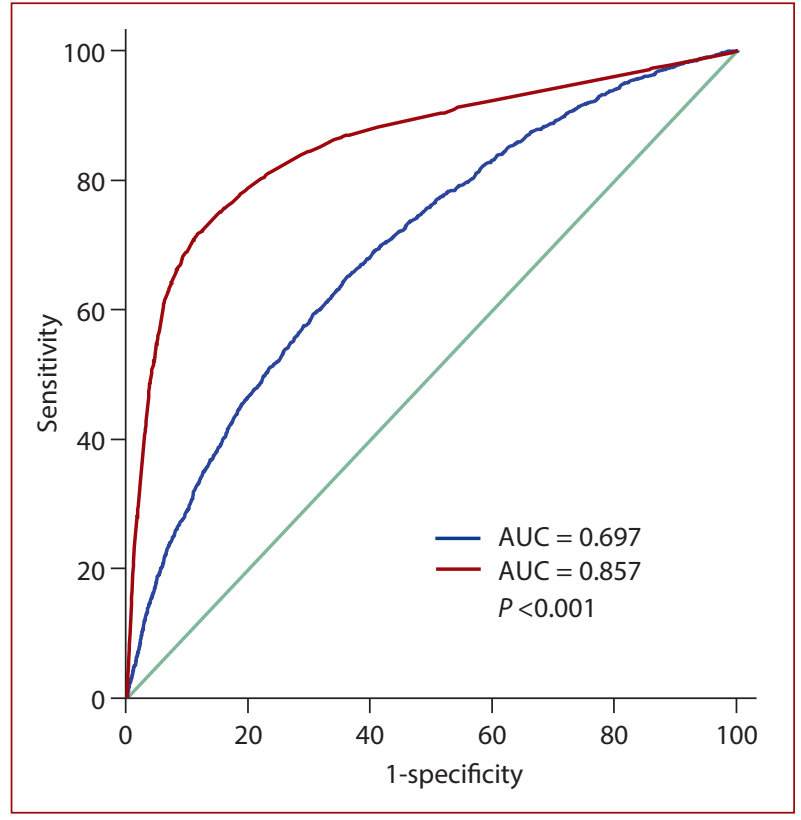

Figure 2. Pairwise comparison of ROC curves for the multivariable logistic regression model for death during the procedure based on (1) clinical factors and (2) pre-hospital and pharmacological factors Abbreviations: see Figure 1

(TASTE) trial. This randomized study had 7244 patients with STEMI. Among them, 901 subjects were diabetic. The study showed a significantly higher all-cause and one-year mortality [18]. Recently, Kim et al. [19] evaluated 4097 patients with STEMI and multi-vessel disease, diabetes, prediabetes, and normoglycemia. They revealed significantly higher mortality among patients with diabetes as compared to those with prediabetes and normoglycemia. In the present study of 113456 STEMI patients selected for invasive treatment, there was a significant relationship between diabetes and death in the cath lab and cardiac arrest during the procedure. 
Chronic renal failure is a well-known factor that worsens the prognosis of STEMI. Brown et al. [20] evaluated a total of 24405 veterans between 2005 and 2010. In that study, chronic renal failure was associated with more common myocardial infarction and a higher risk of death. Between 2007 and 2014, Ismail et al. [21] investigated 6563 patients from the Malaysian National Cardiovascular Disease Database - Percutaneous Coronary Intervention (NCVD-PCI). The study showed a higher cardiovascular risk in patients with diabetes (54.6\%), hypertension (79.2\%), and dyslipidemia (68.8\%). In these groups, the risk of death among patients with chronic renal failure and STEMI was also higher. The present study revealed a significantly higher risk of death in the cath lab and cardiac arrest during the procedure in patients with chronic renal failure.

Other cardiovascular events are associated with the progression of atherosclerosis. Myocardial reinfarction in patients with prior STEMI is the manifestation of such progression. Fraticelli et al. [22] investigated a group of patients with STEMI in the OSCAR trial carried out between 2013 and 2017. The study population consisted of 6306 participants, including 5423 first-presentation STEMI patients and 883 individuals with previous myocardial infarction. There were no significant differences in in-hospital mortality between the groups. The Feedback The Intervention and Treatment Times in ST-Elevation Myocardial Infarction trial (FITT-STEMI) is another large study in STEMI patients with reinfarction. The study population consisted of 12676 subjects. They were subdivided into four groups with accompanying cardiogenic shock and with or without out-of-hospital cardiac arrest. The reinfarction group consisted of 1378 patients. The study showed the lowest mortality in hemodynamically stable patients and the highest death rate in patients with cardiogenic shock but without OHCA. As compared to the two groups with cardiogenic shock, mortality was lower in patients with OHCA and without cardiogenic shock [23].

Another manifestation of the progression of atherosclerosis is acute ischemic stroke complicated by STEMI. Pana et al. [24] studied 9840 patients with myocardial infarction after stroke between 2003 and 2016. Survival was assessed at 1 year, between 1 and 5 years, and between 5 and 10 years. The highest mortality rate was observed at one year. The prognosis of post-stroke myocardial infarction was generally poor [24]. In a large group of patients with STEMI and a history of stroke studied by Hariri et al. [25], the risk of death during hospitalization was significantly higher than in patients without stroke. Similarly in a large study by Liao et al. [26], 211 (2.3\%) of 9180 patients with stroke experienced myocardial infarction in hospital. Of these, $64.9 \%$ died as compared to $35.8 \%$ in the entire study group. Mortality at 1 year after stroke was $56.4 \%$ in patients with myocardial infarction as compared to $21.9 \%$ in the entire study group. In the present study of almost 113500 patients with STEMI, there was a significant relationship between periprocedural death and cardiac arrest in the cath lab in patients with a history of stroke.

Periprocedural prognosis, in this study based on the occurrence of death in the cath lab or cardiac arrest, is determined not only by conventional risk factors such as diabetes, chronic renal failure, previous myocardial infarction, or stroke. New evidence shows that the risk of perioperative death depends also on a history of psoriasis in patients with STEMl; however, these observations are ambiguous. Siudak et al. [27] carried out a large study in 405078 patients who underwent coronary angiography due to acute coronary syndrome. Psoriasis was diagnosed in 1507 (0.4\%) patients. In that study psoriasis was an independent predictor of increased allergic reaction. There were no differences in perioperative mortality in patients with and without psoriasis. Between 2005 and 2016 Karbach et al. [28] in a study in 3307703 patients with myocardial infarction of whom 9028 (0.3\%) had psoriasis showed lower in-hospital mortality rates in psoriatic patients. However, these patients were on average 5 years younger than the remaining subjects. The present study carried out between 2014 and 2019 exclusively in patients with STEMI showed a significantly higher risk of perioperative death and cardiac arrest in the cath lab.

Another very important factor affecting survival and perioperative mortality is the Killip-Kimball class on admission. The index of heart failure severity in patients with acute myocardial infarction was proposed by Killip and Kimball in the 1960s [29]. Now the Killip-Kimball classification is widely used in clinical practice. Oliveira et al. [30] analyzed 5-year mortality data for 1906 patients admitted to the hospital between 1995 and 2011. The results showed a significant relationship between mortality at 5 years and the Killip-Kimball class. The present study in 113456 patients confirms the significant association between PM/sudden cardiac arrest in the cath lab and the Killip-Kimball class on admission.

Some studies describe the paradoxically protective effects of smoking. It is a very interesting phenomenon. Cigarette smoking is a well-known risk factor for STEMI; however, smokers' paradox has been described in the literature. Redfors et al. [31] analyzed 10 randomized studies with STEMI patients undergoing primary $\mathrm{PCI}(\mathrm{n}=2564)$. Smokers had lower in-hospital mortality and shorter hospital stay. The investigators ascribed this paradox to the younger age of the patients and fewer comorbidities. Other investigators confirmed the smokers' paradox [32].

Diabetes is a well-known risk factor for poor outcomes in patients with STEMI. A large study based on the Polish Registry of Acute Coronary Syndromes shows that diabetes increases the prevalence of pulmonary edema, cardiogenic shock, cardiac arrest, major bleeding, and in-hospital mortality but has no impact on stroke or transient ischemic attack [33]. The National Emergency Medical Services Management Support System, a unique information and 
communication technology system, was developed to reduce the burden of ST-segment elevation myocardial infarction (STEMI) in Poland. A recent study has shown that there are many differences in pre-hospital STEMI treatment between provinces in Poland [34]. These 2 studies and the ORPKI registry may provide helpful insights to improve the treatment of patients with STEMI.

Summing up, the study carried out in a large group of STEMI patients selected for invasive treatment shows a significant relationship between conventional and less common (psoriasis) risk factors and PM.

\section{CONCLUSIONS}

Of all factors, diabetes, renal failure, previous myocardial infarction, previous stroke, psoriasis, and the Killip-Kimball class had the strongest influence on perioperative mortality and sudden cardiac arrest. Models of logistic regression based on pre-hospital and pharmacological factors fit better than models based on comorbidities i.e., the former better distinguish between positive and negative cases. Risk stratification based on the above-mentioned most important risk factors facilitates the team's preparation for the procedure.

\section{Supplementary material}

Supplementary material is available at https://journals. viamedica.pl/kardiologia_polska.

\section{Article information}

Conflict of interest: None declared.

Open access: This article is available in open access under Creative Common Attribution-Non-Commercial-No Derivatives 4.0 International (CC BY-NC-ND 4.0) license, allowing to download articles and share them with others as long as they credit the authors and the publisher, but without permission to change them in any way or use them commercially. For commercial use, please contact the journal office at kardiologiapolska@ptkardio.pl.

How to cite: Sielski J, Kaziród-Wolski K, Siudak Z. Risk of perioperative death and sudden cardiac arrest: A study of 113456 cases from the National Registry of Invasive Cardiology Procedures (ORPKI) for estimation of the perioperative prognosis. Kardiol Pol. 2021; 79(12): 1328-1334, doi: 10.33963/KP.a2021.0133.

\section{REFERENCES}

1. Cheung W, Flynn M, Thanakrishnan G, et al. Survival after out-of-hospital cardiac arrest in Sydney, Australia. Crit Care Resusc. 2006; 8(4): 321-327, indexed in Pubmed: 17227269.

2. Chan PS, McNally B, Tang F, et al. CARES Surveillance Group. Recent trends in survival from out-of-hospital cardiac arrest in the United States. Circulation. 2014; 130(21): 1876-1882, doi: 10.1161/CIRCULATION-AHA.114.009711, indexed in Pubmed: 25399396.

3. Benjamin EJ, Virani SS, Callaway CW, et al. American Heart Association Council on Epidemiology and Prevention Statistics Committee and Stroke Statistics Subcommittee. Heart Disease and Stroke Statistics - 2018 update: a report from the American Heart Association. Circulation. 2018; 137(12): e67-e492, doi: 10.1161/CIR.0000000000000558, indexed in Pubmed: 29386200.

4. Neumar RW, Shuster M, Callaway CW, et al. Part 1: executive summary: 2015 American Heart Association quidelines update for cardiopulmonary resuscitation and emergency cardiovascular care. Circulation. 2015;
132(18 Suppl 2): S315-S367, doi: 10.1161/CIR.0000000000000252, indexed in Pubmed: 26472989.

5. Monsieurs KG, Nolan JP, Bossaert LL, et al. ERC Guidelines 2015 Writing Group. European Resuscitation Council Guidelines for Resuscitation 2015: section 1. Executive summary. Resuscitation. 2015; 95:1-80, doi: 10.1016/j. resuscitation.2015.07.038, indexed in Pubmed: 26477410.

6. Andersen LW, Holmberg MJ, Berg KM, et al. In-Hospital cardiac arrest: a review. JAMA. 2019; 321(12): 1200-1210, doi: 10.1001/jama.2019.1696, indexed in Pubmed: 30912843.

7. Kontos MC, Scirica BM, Chen AY, et al. NCDR. Cardiac arrest and clinical characteristics, treatments and outcomes among patients hospitalized with ST-elevation myocardial infarction in contemporary practice: A report from the National Cardiovascular Data Registry. Am Heart J. 2015; 169(4): 515-522.e1, doi: 10.1016/j.ahj.2015.01.010, indexed in Pubmed: 25819858.

8. Lettieri C, Savonitto S, De Servi S, et al. LombardIMA Study Group. Emergency percutaneous coronary intervention in patients with ST-elevation myocardial infarction complicated by out-of-hospital cardiac arrest: early and medium-term outcome. Am Heart J. 2009; 157(3): 569-575.e1, doi: 10.1016/j.ahj.2008.10.018, indexed in Pubmed: 19249431.

9. Kunadian V, Bawamia B, Maznyczka A, et al. Outcomes following primary percutaneous coronary intervention in the setting of cardiac arrest: a registry database study. Eur Heart J Acute Cardiovasc Care. 2015; 4(1): 6-15, doi: 10.1177/2048872614534079, indexed in Pubmed: 24818951.

10. Demirel F, Rasoul S, Elvan A, et al. Impact of out-of-hospital cardiac arrest due to ventricular fibrillation in patients with ST-elevation myocardial infarction admitted for primary percutaneous coronary intervention: Impact of ventricular fibrillation in STEMI patients. Eur Heart J Acute Cardiovasc Care. 2015; 4(1): 16-23, doi: 10.1177/2048872614547448, indexed in Pubmed: 25114328

11. Jernberg T. Swedeheart Annual Report 2015. In: Karolinska University Hospital, Huddinge, Stockholm, 2016. https://ki.se/sites/default/files/migrate/ki_annualreport_2015_webb.pdf (April 14, 2021).

12. Widimsky P, Wijns W, Fajadet J, et al. European Association for Percutaneous Cardiovascular Interventions. Reperfusion therapy for ST elevation acute myocardial infarction in Europe: description of the current situation in 30 countries. Eur Heart J. 2010; 31(8): 943-957, doi: 10.1093/eurheartj/ehp492, indexed in Pubmed: 19933242.

13. 20 MedCalc Statistical Software. Version 19.7. MedCalc Software; 2021. https://www.medcalc.org (March 15, 2021).

14. Gąsior M, Pres D, Wojakowski W, et al. Causes of hospitalization and prognosis in patients with cardiovascular diseases. Secular trends in the years 2006-2014 according to the SILesian CARDiovascular (SILCARD) database. Pol Arch Med Wewn. 2016; 126(10): 754-762, doi: 10.20452/pamw.3557, indexed in Pubmed: 27650214.

15. Karwowski J, Gierlotka M, Gąsior M, et al. Relationship between infarct artery location, acute total coronary occlusion, and mortality in STEMI and NSTEMI patients. Pol Arch Intern Med. 2017; 127(6): 401-411, doi: 10.20452/pamw.4018, indexed in Pubmed: 28475171.

16. Januszek R, Siudak Z, Malinowski KP, et al. Aspiration thrombectomy in patients with acute myocardial infarction-5-year analysis based on a large national registry (ORPKI). J Clin Med. 2020; 9(11): 3610, doi: 10.3390/jcm9113610, indexed in Pubmed: 33182436.

17. Tokarek T, Siudak Z, Dziewierz A, et al. Clinical outcomes in nonagenarians undergoing a percutaneous coronary intervention: data from the ORPKI Polish National Registry 2014-2016. Coron Artery Dis. 2018; 29(7): 573-578, doi: 10.1097/MCA.0000000000000649, indexed in Pubmed: 29912784.

18. Fröbert O, Lagerqvist Bo, Olivecrona GK, et al. TASTE Trial. Thrombus aspiration during ST-segment elevation myocardial infarction. N Engl J Med. 2013;369(17): 1587-1597, doi: 10.1056/NEJMoa1308789, indexed in Pubmed: 23991656.

19. Kim YH, Her AY, Jeong MHo, et al. Two-Year clinical outcomes between prediabetic and diabetic patients with STEMI and multivessel disease who underwent successful PCl using drug-eluting stents. Angiology. 2021;72(1):50-61, doi: 10.1177/0003319720949311, indexed in Pubmed: 32806925 .

20. Brown JR, Solomon RJ, Robey RB, et al. Chronic kidney disease progression and cardiovascular outcomes following cardiac catheterization - a pop- 
ulation-controlled study. J Am Heart Assoc. 2016; 5(10): e003812, doi: 10.1161/JAHA.116.003812, indexed in Pubmed: 27742616.

21. Ismail MD, Jalalonmuhali M, Azhari Z, et al. NCVD-PCl investigators. Outcomes of STEMI patients with chronic kidney disease treated with percutaneous coronary intervention: the Malaysian National Cardiovascular Disease Database - Percutaneous Coronary Intervention (NCVD-PCI) registry data from 2007 to 2014. BMC Cardiovasc Disord. 2018; 18(1): 184, doi: 10.1186/s12872-018-0919-9, indexed in Pubmed: 30249197.

22. Fraticelli L, Kleitz O, Claustre C, et al. RESCUe Research Group. Comparison of the pathways of care and life courses between first-time ST-elevation myocardial infarction (STEMI) and STEMI with prior MI: findings from the OSCAR registry. BMJ Open. 2020; 10(11): e038773, doi: 10.1136/bmjopen-2020-038773, indexed in Pubmed: 33154054.

23. Scholz KH, Maier SKG, Maier LS, et al. Impact of treatment delay on mortality in ST-segment elevation myocardial infarction (STEMI) patients presenting with and without haemodynamic instability: results from the German prospective, multicentre FITT-STEMI trial. Eur Heart J. 2018; 39(13): 1065-1074, doi: 10.1093/eurheartj/ehy004, indexed in Pubmed: 29452351.

24. Pana $T A$, Wood AD, Mamas MA, et al. Norfolk and Norwich Stroke and TIA Register Steering Committee Collaborators. Myocardial infarction after acute ischaemic stroke: Incidence, mortality and risk factors. Acta Neurol Scand. 2019; 140(3): 219-228, doi: 10.1111/ane.13135, indexed in Pubmed: 31140583.

25. Hariri E, Tisminetzky M, Lessard D, et al. Twenty-five-year (1986-2011) trends in the incidence and death rates of stroke complicating acute myocardial infarction. Am J Med. 2018; 131(9): 1086-1094, doi: 10.1016/j. amjmed.2018.04.018, indexed in Pubmed: 29730362.

26. Liao J, O'Donnell MJ, Silver FL, et al. Investigators of the Registry of the Canadian Stroke Network. In-hospital myocardial infarction following acute ischaemic stroke: an observational study. Eur J Neurol. 2009; 16(9): 1035-1040, doi: 10.1111/j.1468-1331.2009.02647.x, indexed in Pubmed: 19614964.
27. Siudak Z, Wysocka-Dubielecka K, Malinowski K, et al. Psoriasis is an independent predictor of increased risk of allergic reaction during percutaneous coronary interventions. Big data analysis from the Polish National PCI Registry (ORPKI). Cardiol J. 2020; 27(3): 278-284, doi: 10.5603/CJ.a2018.0076, indexed in Pubmed: 30155870.

28. Karbach S, Hobohm L, Wild J, et al. Impact of psoriasis on mortality rate and outcome in myocardial infarction. J Am Heart Assoc. 2020; 9(18): e016956, doi: 10.1161/JAHA.120.016956, indexed in Pubmed: 32914667.

29. Killip T, Kimball J. Treatment of myocardial infarction in a coronary care unit. A two year experience with 250 patients. Am J Cardiol. 1967; 20(4): 457-464, doi: 10.1016/0002-9149(67)90023-9, indexed in Pubmed: 6059183.

30. Mello BH, Oliveira GB, Ramos RF, et al. Validation of the Killip-Kimball classification and late mortality after acute myocardial infarction. Arq Bras Cardiol. 2014; 103(2): 107-117, doi: 10.5935/abc.20140091, indexed in Pubmed: 25014060.

31. Redfors B, Furer A, Selker HP, et al. Effect of smoking on outcomes of primary PCl in patients with STEMI. J Am Coll Cardiol. 2020; 75(15): 1743-1754, doi: 10.1016/j.jacc.2020.02.045, indexed in Pubmed: 32299585.

32. Gennaro G, Brener SJ, Redfors B, et al. Effect of smoking on infarct size and major adverse cardiac events in patients with large anterior ST-elevation myocardial infarction (from the INFUSE-AMI trial). Am J Cardiol. 2016; 118(8): 1097-1104, doi: 10.1016/j.amjcard.2016.07.019, indexed in Pubmed: 27553094.

33. Niedziela JT, Hiczkiewicz J, Kleinrok A, et al.Prevalence, characteristics, and prognostic implications of type 2 diabetes in patients with myocardial infarction: the Polish Registry of Acute Coronary Syndromes (PLACS) annual 2018 report. Kardiol Pol. 2020; 78(3): 243-246, doi: 10.33963/KP.15189, indexed in Pubmed: 32063598.

34. Nadolny K, Ładny JR, Gałązkowski R, et al. Medical emergency team interventions in patients with ST-segment elevation myocardial infarction in Poland in 2018. Kardiol Pol. 2020; 78(4):292-299, doi: 10.33963/KP.15222, indexed in Pubmed: 32124868. 